\title{
DNA methylation and differentiation: HOX genes in muscle cells
}

Koji Tsumagari ${ }^{1}$, Carl Baribault ${ }^{2}$, Jolyon Terragni ${ }^{3}$, Sruti Chandra ${ }^{1}$, Chloe Renshaw ${ }^{1}$, Zhiyi Sun ${ }^{3}$, Lingyun Song ${ }^{4}$, Gregory E Crawford ${ }^{4}$, Sriharsa Pradhan ${ }^{3}$, Michelle Lacey ${ }^{2}$ and Melanie Ehrlich ${ }^{1,5^{*}}$

\begin{abstract}
Background: Tight regulation of homeobox genes is essential for vertebrate development. In a study of genome-wide differential methylation, we recently found that homeobox genes, including those in the HOX gene clusters, were highly overrepresented among the genes with hypermethylation in the skeletal muscle lineage. Methylation was analyzed by reduced representation bisulfite sequencing (RRBS) of postnatal myoblasts, myotubes and adult skeletal muscle tissue and 30 types of non-muscle-cell cultures or tissues.
\end{abstract}

Results: In this study, we found that myogenic hypermethylation was present in specific subregions of all four HOX gene clusters and was associated with various chromatin epigenetic features. Although the $3^{\prime}$ half of the HOXD cluster was silenced and enriched in polycomb repression-associated $\mathrm{H} 3$ lysine 27 trimethylation in most examined cell types, including myoblasts and myotubes, myogenic samples were unusual in also displaying much DNA methylation in this region. In contrast, both HOXA and HOXC clusters displayed myogenic hypermethylation bordering a central region containing many genes preferentially expressed in myogenic progenitor cells and consisting largely of chromatin with modifications typical of promoters and enhancers in these cells. A particularly interesting example of myogenic hypermethylation was HOTAIR, a HOXC noncoding RNA gene, which can silence HOXD genes in trans via recruitment of polycomb proteins. In myogenic progenitor cells, the preferential expression of HOTAIR was associated with hypermethylation immediately downstream of the gene. Other HOX gene regions also displayed myogenic DNA hypermethylation despite being moderately expressed in myogenic cells. Analysis of representative myogenic hypermethylated sites for 5-hydroxymethylcytosine revealed little or none of this base, except for an intragenic site in HOXB5 which was specifically enriched in this base in skeletal muscle tissue, whereas myoblasts had predominantly 5-methylcytosine at the same CpG site.

Conclusions: Our results suggest that myogenic hypermethylation of HOX genes helps fine-tune HOX sense and antisense gene expression through effects on 5' promoters, intragenic and intergenic enhancers and internal promoters. Myogenic hypermethylation might also affect the relative abundance of different RNA isoforms, facilitate transcription termination, help stop the spread of activation-associated chromatin domains and stabilize repressive chromatin structures.

Keywords: Alternative splicing, DNA methylation, Enhancers, H3K4 trimethylation, HOTAIR, HOX genes, 5-Hydroxymethylcytosine, Muscle, Myoblasts, Polycomb repression

\footnotetext{
* Correspondence: ehrlich@tulane.edu

'Hayward Human Genetics Program and Tulane Cancer Center, Tulane

Health Sciences Center, New Orleans LA, USA

${ }^{5}$ Center for Bioinformatics and Genomics, Tulane Health Sciences Center,

New Orleans, LA, USA

Full list of author information is available at the end of the article
}

\section{Biomed Central}

(c) 2013 Tsumagari et al.; licensee BioMed Central Ltd. This is an Open Access article distributed under the terms of the Creative Commons Attribution License (http://creativecommons.org/licenses/by/2.0), which permits unrestricted use, distribution, and reproduction in any medium, provided the original work is properly cited. 


\section{Background}

HOX genes are a subset of homeobox genes found in four highly conserved gene clusters on different chromosomes. They encode transcription factors essential for determining the vertebrate body axes during embryonic development and for guiding other aspects of prenatal and postnatal differentiation and postnatal homeostasis $[1,2]$. Probably as a derangement of these normal roles, $H O X$ genes are often hypermethylated in cancer [3]. During embryogenesis, the genes within a given $H O X$ cluster are activated sequentially in a collinear manner corresponding to the body plan. Because of their pivotal differentiation-linked roles, HOX genes must be regulated in a precise spatiotemporal manner, which makes their cell type-specific epigenetics of particular interest. The collinear activation of $H O X$ genes during embryogenesis is mediated by the remodeling of chromatin from a repressive to a transcription-permissive state through changes in histone modifications, especially repressive histone H3 trimethylation at lysine 27 (H3K27me3) and activation-associated $\mathrm{H} 3 \mathrm{~K} 4$ tri-, di- and mono-methylation (H3K4me3, 2 and 1) [4].

We have been studying the epigenetic markers associated with the skeletal muscle lineage, with emphasis on DNA methylation but also incorporating analysis of chromatin epigenetics. DNA methylation is known to vary markedly among different tissues and cell types [5-9]. Human myoblasts (Mb) are an attractive model for analysis of differentiation because they can be efficiently differentiated into very large, multinucleated, postmitotic myotubes (Mt) in vitro and can be compared with skeletal muscle tissue, which is largely derived from such myogenic progenitors. The differentiation of $\mathrm{Mb}$ to Mt is relevant not only to the formation of skeletal muscle during embryogenesis but also to postnatal repair of muscle [10].

By reduced representation bisulfite sequencing (RRBS) [6], we recently profiled $\mathrm{CpG}$ methylation throughout the genome in the muscle lineage using $\mathrm{Mb}$, Mt and skeletal muscle for comparison to 17 nonmyogenic cell cultures and 14 normal nonmuscle tissues [11]. RRBS, which has single-base resolution, detects approximately $5 \%$ of genomic CpGs in a wide variety of sequences, namely, gene bodies and intergenic regions; $\mathrm{CpG}$ islands, which account for approximately $50 \%$ of RRBS-detected CpGs [6], and nonisland sequences; and single-copy and repeated sequences. Using stringent criteria, we identified differentially methylated CpG sites by comparing the set of myoblasts plus myotubes (MbMt) with many diverse nonmuscle cell cultures derived from normal tissues [11]. We similarly mapped CpGs differentially methylated in skeletal muscle vs. nonmuscle tissue. The RRBS-detected CpG sites in $\mathrm{Mb}$ and $\mathrm{Mt}$ were much more similar to each other than to other cell lineages. When sites with myogenic differential methylation were mapped to the nearest gene and then these genes were examined for related functional terms, homeobox genes were found to be one of the most strongly overrepresented classes among the MbMt-hypermethylated genes.

Homeobox genes include the $H O X$ genes, which are oriented in the same direction in a given $H O X$ gene cluster so that their intracluster location can be referred to as $5^{\prime}$ or $3^{\prime}$ according to the direction of transcription [12]. This uniform directionality reflects the generation of the archetypal cluster by gene duplication. The ancestral $H O X$ gene cluster was in turn replicated to produce four gene clusters. These contain paralogous genes related by sequence similarity and intracluster position and were assigned to the same number group. Paralogous $H O X$ genes have many similarities in function but can also display distinct functionality $[12,13]$.

The HOXA/Hoxa cluster is implicated in regulating mouse limb bud development (especially Hoxa9-Hoxa13) [14]. Hoxa9 and Hoxa10 are expressed in the murine $\mathrm{C} 2 \mathrm{C} 12 \mathrm{Mb}$ cell line and in limb muscles during embryogenesis and postnatally, but Hoxa10 was repressed during muscle regeneration following injury [15]. Targeted disruption of Hoxa13 increased the level of expression of the myogenic transcription factor MyoD in embryonic murine forelimb [16]. Hoxa1 coordinates the expression of other Hoxa genes in murine embryonic stem cells upon induction by retinoic acid, leading to demethylation of H3K27me3 [17]. HOXA/Hoxa genes are expressed in some postnatal lineages, including hematopoietic cells [18], adult lung [19] and endometrium [20]. Unlike HOXA/Hoxa genes, $H O X B / H o x b$ genes are not detectably expressed in murine limb muscle during embryogenesis [15]. However, Hoxb5 is implicated in determining limb positions along the anteroposterior axis [21]. Among other functions, $H O X B / H o x b$ genes are likely to play a role in lung development [19] and hematopoiesis [22].

Murine Hoxc genes are also expressed in the skeletal muscle lineage, including Hoxc12 in embryonic myoblasts [23] and Hoxc9-Hoxc13 in the embryonic muscle hindlimb, but not in the forelimb [15]. Hoxc6, Hoxc9, Hoxc10 and Hoxc11 are expressed in murine $\mathrm{C} 2 \mathrm{C} 12 \mathrm{Mb}$ and Mt [15] and during the formation of other organ systems, such as the nervous system [24]. Among the postnatal tissues with specific expression of HOXC/Hoxc genes are muscle [15], lymphocytes [25], mammary glands [26], skin and keratinocytes [27]. HOXD/Hoxd genes, like HOXA/Hoxa genes, appear to play especially important roles in limb and digit formation $[14,28]$ as well as in the development of other organs, such as the formation of the terminal regions of the digestive and urogenital tracts [12]. However, Hoxd11 is expressed in embryonic muscle, but not in postnatal muscle or $\mathrm{C} 2 \mathrm{C} 12 \mathrm{Mb}$ or Mt [15]. 
Differential expression of $H O X / H o x$ genes in a spatially and temporally specific manner is associated with chromatin modification [29-31], expression of ncRNAs (including miRNAs) in cis or trans [32-34], long-distance enhancers outside the $H O X$ clusters as well as local enhancers [35] and three-dimensional chromatin architecture [4,36]. Studies of specific $H O X / H o x$ genes have revealed tissue-specific DNA methylation, which is likely to help lock in complicated expression patterns for $H O X$ genes and possibly help to establish these expression patterns [37-40]. In a wholegenome analysis of DNA methylation, the four $H O X$ gene clusters were found to be hypomethylated in human embryonic stem cells (ESCs) relative to fibroblast-like derivatives of ESC, neonatal foreskin fibroblasts and blood monocytes [41]. To the best of our knowledge, the present study is the first to use single-base resolution profiling of DNA methylation to investigate all the HOX clusters in a wide variety of normal cell cultures and tissues. We also correlated DNA epigenetic differences with differential chromatin epigenetics and gene expression. We found that the variety of $H O X$ genes' functions is reflected in their developmentally associated DNA methylation patterns, which had diverse relationships with gene expression.

In addition, we examined whether DNA hypermethylation in myogenic progenitor cells involves 5methylcytosine $(5 \mathrm{mC})$ or 5 -hydroxymethylcytosine $(5 \mathrm{hmC})$ because they cannot be distinguished by RRBS or most other types of DNA methylation analysis [42]. In mammalian DNA, $5 \mathrm{hmC}$ is the sixth genetically programmed base. It is usually very much less abundant than $5 \mathrm{mC}$ and serves as an intermediate in DNA demethylation as well as a stable DNA base $[43,44]$. Increases in $5 \mathrm{hmC}$ and decreases in $5 \mathrm{mC}$ have been reported in HOXA1 and HOXA2 upon induction of differentiation of the NT2 embryonal carcinoma cell line by retinoic acid, which derepresses $H O X$ genes in a collinear manner [45]. Discriminating between $5 \mathrm{mC}$ and $5 \mathrm{hmC}$ is important because they seem to typically play very different roles in the control of gene expression, usually repression at cis-acting transcription control elements for $5 \mathrm{mC}$ and activation at enhancers for $5 \mathrm{hmC}$ $[42,46]$. Therefore, we quantified $5 \mathrm{mC}$ and $5 \mathrm{hmC}$ at five representative $\mathrm{CpG}$ sites in the four $H O X$ clusters of muscle and nonmuscle samples by enzymatic assay.

\section{Results and discussion}

\section{Myogenic DNA hypermethylation at HOXD genes vs.} H3K27me3 in many cell types

To identify myogenic differential methylation in $H O X$ gene clusters, we analyzed RRBS data from the ENCODE project ([11]; http://genome.ucsc.edu/; DNA methylation by RRBS; HudsonAlpha Institute for Biotechnology, Huntsville, AL, USA). The methylome profiles that we used were generated from our $\mathrm{Mb}$ and Mt samples plus 16 other types of cell culture and skeletal muscle plus 14 types of normal tissue. The Mb samples were derived from biopsies, and aliquots were differentiated to Mt. Importantly, all had been characterized immunocytochemically as previously described [11]. The nonmuscle cultures were untransformed cells, with the exception of lymphoblastoid cell lines (LCLs). We determined significant myogenic hypermethylation or hypomethylation using stringent criteria, namely, at least a $50 \%$ difference in methylation in $\mathrm{Mb}$ and $\mathrm{Mt}$ (as a set, MbMt) vs. the nonmyogenic cell cultures or in skeletal muscle tissue vs. nonmuscle tissue at a significance level of $P<0.01$ using fitted binomial regression models at each monitored CpG site [11]. This analysis involved our recently developed algorithm that adjusts single-site $P$ values for coverage score and sample size. We then plotted the sites with myogenic differential methylation to the nearest gene and subgene region as illustrated for $H O X$ genes in Additional file 1. All our references to myogenic differential methylation met the above requirements for statistical significance.

In the $H O X D$ gene cluster, many sites were hypermethylated in the MbMt set vs. nonmuscle cell cultures or in skeletal muscle tissue vs. nonmuscle tissues, as shown in Figure 1a. Figure 1b displays the coverage of RRBS in this region by exhibiting DNA methylation data tracks from the UCSC Genome Browser for representative samples. One of the subregions with the most myogenic hypermethylation in both progenitor cells and tissues was in the vicinity of HOXD4 and had 38 MbMt-hypermethylated sites and 33 skeletal muscle-hypermethylated sites (Figure 1a, tan highlighting, and Additional file 2). The two clusters of MbMthypermethylated sites in the HOXD4 upstream region surround a retinoic acid-sensitive mesodermal enhancer [47] and are near the adjacent MIR1OB gene (Figure 1), whose methylation was implicated in gene silencing in cis in gastric cancer [32]. Both DNA methylation and $\mathrm{H} 3 \mathrm{~K} 27 \mathrm{me} 3$ were seen at the MIR $10 B$ promoter region in human mammary epithelial cells (HMEC) in a previous study [48] as well as in the present study (Figure 1 and Additional file 2). Our analysis of RNA-seq data (ENCODE/California Institute of Technology; http:// genome.ucsc.edu/; [49]) by Cufflinks [50], a program which evaluates RNA-seq profiles to determine steadystate amounts of different RNA isoforms, indicated that human umbilical vein endothelial cells (HUVEC) expressed this gene abundantly, whereas less than 200 times as much HOXD4 RNA was detected in Mb, epidermal keratinocytes (NHEK), lung fibroblasts (NHLF), ESC and an LCL (Additional file 1). Only HUVEC did not have the repressive polycomb group chromatin marks at HOXD4 and throughout most of the HOXD cluster (Figure 1d). However, the predominant, 5.1-kb HUVEC transcript began upstream of HOXD4 near the MIR1OB gene and extended past the 3 ' end of $H O X D 4$. A second, 


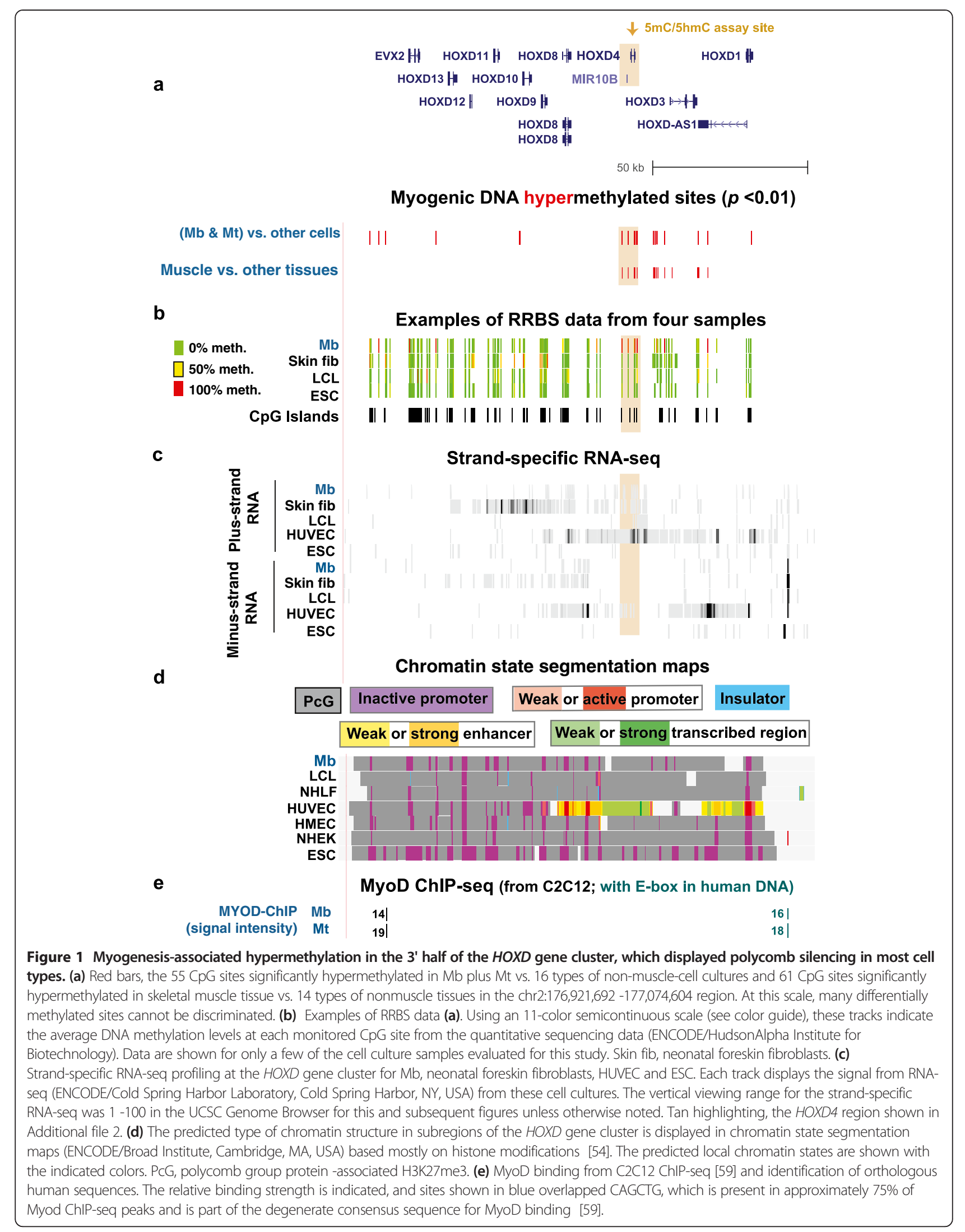


noncoding transcript was seen in HUVEC (ENST00000 465649), whose transcription begins within the single HOXD4 intron. The myogenic intragenic hypermethylated sites in HOXD4 surround or overlap this alternative transcription start site (TSS; pink triangle, Additional file 2). Myogenic hypermethylation of the intron might help suppress the use of a secondary, intronic promoter.

Not only was HOXD4 silent in most of the examined cells types, including $\mathrm{Mb}$, but this was also the case for the rest of the HOXD cluster, especially the 3 ' half of the cluster (Figure 1c). Similarly, there was silencing-associated H3K27me3 throughout the gene cluster in $\mathrm{Mb}$, Mt and most examined nonmyogenic cell types (Figure 1d, PcG, and Additional file 3) as determined by whole-genome chromatin immunoprecipitation/ next-generation DNA sequencing (H3K27me3 ChIP-seq; ENCODE/Broad Institute, http://genome.ucsc.edu/). There was an unusually high concentration of $\mathrm{CpG}$ islands in the HOXD cluster and the other three $H O X$ clusters (Figures 1, 2, 3, 4, 5 and 6), but this cannot explain the myogenic hypermethylation in $H O X$ gene clusters. For example, there was a much higher density of MbMthypermethylated sites in the $3^{\prime}$ half of the HOXD gene cluster relative to the $5^{\prime}$ half, but not a higher density of CpG islands (Figure 1a).

An important question is raised by our finding of much myogenesis-associated DNA hypermethylation in the 3' half of the HOXD cluster while H3K27me3 was seen throughout this region in most examined cell types, including $\mathrm{Mb}$ and Mt. Why did the many examined populations of myogenic cells display DNA hypermethylation in this multigene region compared with other cell types, even though the myogenic and nonmyogenic cells shared polycomb silencing which might have sufficed for repression of genes in this region [51]? Although regions of DNA methylation and H3K27me3 sometimes overlap, the relationships between these two epigenetic markers are varied and region-specific [52]. Our findings could be explained most easily by the hypothesis that, for the $3^{\prime}$ half of $H O X D$, polycomb group silencing at the chromatin level does not suffice for repression of 3' HOXD genes in $\mathrm{Mb}$ and $\mathrm{Mt}$, and, specifically in these cells, H3K27me3 needs to be supplemented with DNA methylation. Without the DNA hypermethylation, myogenic progenitor cells might be more susceptible to leaky expression of 3' HOXD genes than are most other cell types. Alternatively, $H O X D$-encoded proteins or ncRNAs generated from the $3^{\prime}$ half of the cluster might be deleterious specifically to myogenic progenitor cells. Consistent with a combined role of DNA methylation and H3K27me3 in some types of HOX/Hox gene regulation, recently it was shown that experimentally induced DNA hypomethylation in mouse embryonic fibroblasts led to decreased H3K27me3 at Hox genes, including genes in the 3' half of the Hoxd gene cluster [53]. Some Hox genes were shown to be derepressed upon DNA demethylation. Our study suggests that the roles of DNA methylation of $H O X$ genes during development are more nuanced than can be seen in a study of one cell type because NHLF (IMR90), ESC and LCL samples exhibited much H3K27me3 in the 3' half of the HOXD cluster despite very little DNA methylation there (Figures $1 \mathrm{~b}$ and $1 \mathrm{~d}$, Additional file 3). In contrast, $\mathrm{Mb}$ and $\mathrm{Mt}$ displayed both H3K27me3 and much DNA methylation in this region.

\section{Myogenic hypermethylation in the HOXC cluster bordering an $\mathrm{H} 3 \mathrm{~K} 4 \mathrm{me} 3$-rich multigenic region}

MbMt-hypermethylation was also seen in the HOXC cluster (Figure 2a), but, unlike HOXD genes, many HOXC genes were moderately or strongly expressed in $\mathrm{Mb}$ and Mt but not in NHLF, LCL, ESC and HUVEC samples (ENCODE/RNA-seq, California Institute of Technology and Cold Spring Harbor Laboratory; Figure 2c and Additional file 1). Foreskin fibroblasts were the other examined cell type that displayed considerable expression of $H O X C$ genes, although less than for Mb (Figure 2c, skin fib). Figure $2 \mathrm{~d}$ shows a distillation of ChIP-seq chromatin epigenetic data (H3K4me1, 2 or 3; H3K27Ac; H3K9Ac; H3K27me3; H3K36me3; H4K20me1; and CTCF binding) by Ernst et al. using a multivariate hidden Markov model (ENCODE/Broad Institute; [54]) to predict chromatin states (color-coded chromatin state segmentation maps). In much of the central, multigenic region of the $H O X C$ cluster in $\mathrm{Mb}$ and $\mathrm{Mt}$, the chromatin state segmentation map shows chromatin with the features of a strong promoter, especially a strong signal for H3K4me3. The H3K4me3 was present in broad intragenic and intergenic subregions in $\mathrm{Mb}$ (Figure $2 \mathrm{~d}, \mathrm{Mb}$, red subregions), as was found for transcribed HOX gene clusters in murine embryonic fibroblasts [30]. This active promoter-like (or active enhancer-like [55]) chromatin rich in H3K4me3 in the middle of the $H O X C$ gene cluster was interspersed with a type of chromatin typically associated with active enhancers (H3K27Ac plus H3K4me1; Figure 2d, Mb, orange subregions). We refer to such a multigenic region consisting largely of chromatin with the typical characteristics of active promoters and enhancers as a P/Elike domain. The P/E-like domain probably reflects, in part, the high density of ncRNA genes, including undocumented ones, and alternative transcription start sites within $H O X$ gene clusters [56-58]. This $\mathrm{P} / \mathrm{E}$ domain is also predicted to contain a MYOD binding site (Figure 2e) because it contains a sequence which is orthologous to a genomic sequence in $\mathrm{C} 2 \mathrm{C} 12$ mouse $\mathrm{Mb}$ and $\mathrm{Mt}$ samples that bound MyoD in MyoD-ChIP-seq profiles [59]. Moreover, this site in the human genome has a centrally located CAGCTG E-box, which is found in many MYOD/MyoD binding sites [59]. 


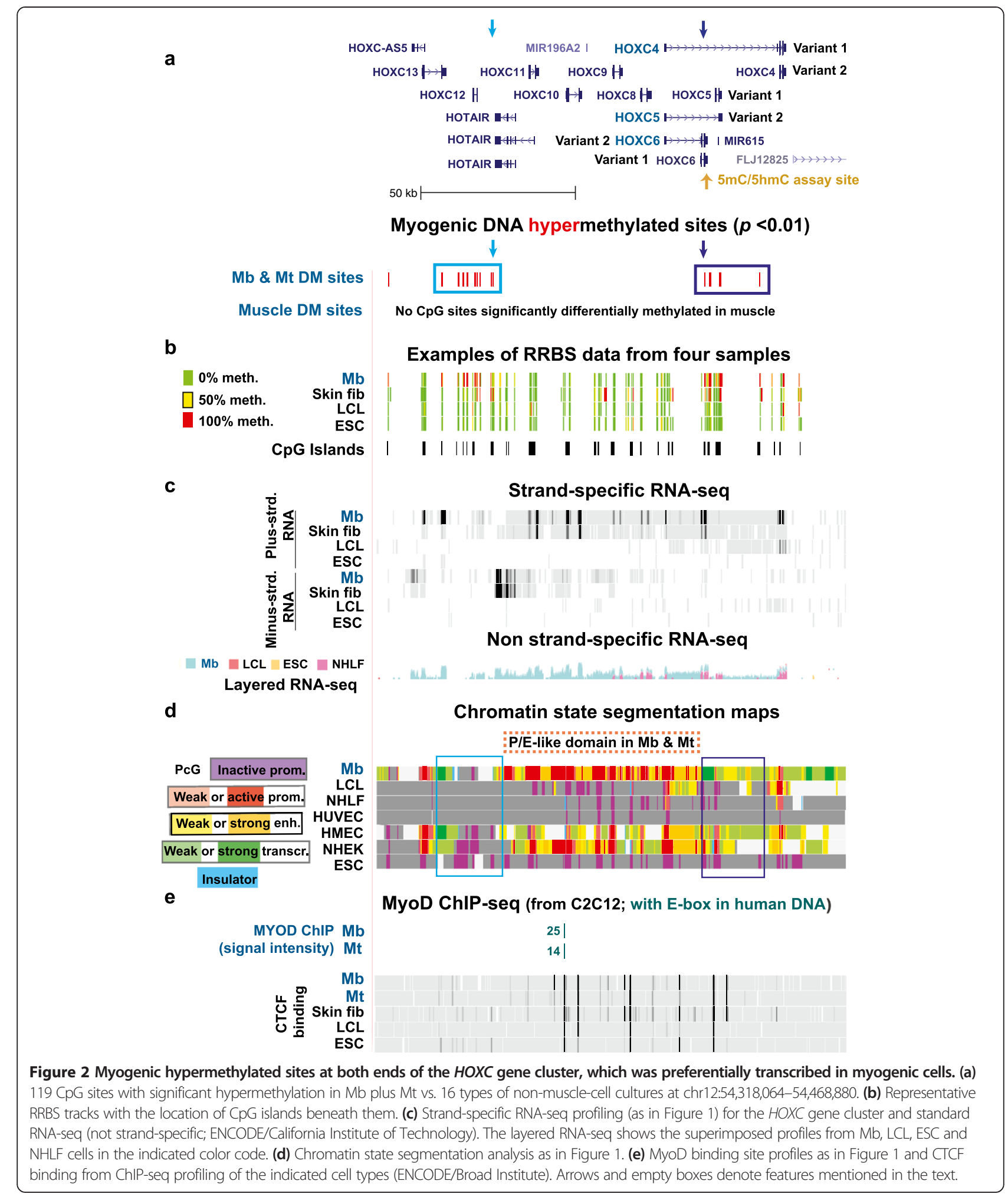

Within a 650-kb region centered over the approximately $130 \mathrm{~kb} H O X C$ cluster, Mb displayed a P/E-like domain only at the $H O X C$ cluster, and this cluster was the most prominent gene region with myogenesis-associated gene expression (Figures 3c and 3d). Many strong C2C12inferred MYOD sites were located outside the HOXC cluster (Figure 3a). We hypothesize that these may be part of long-distance, tissue-specific $H O X$ enhancers, like those 


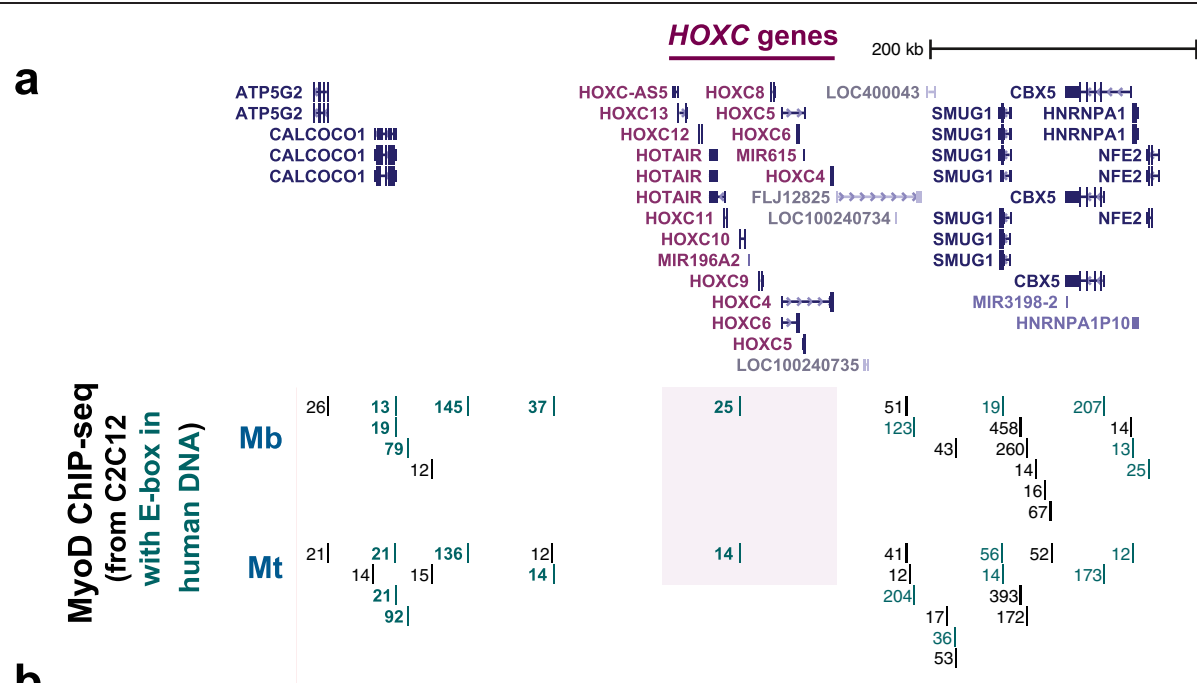

Myogenic DNA hypermethylated sites $(p<0.01)$
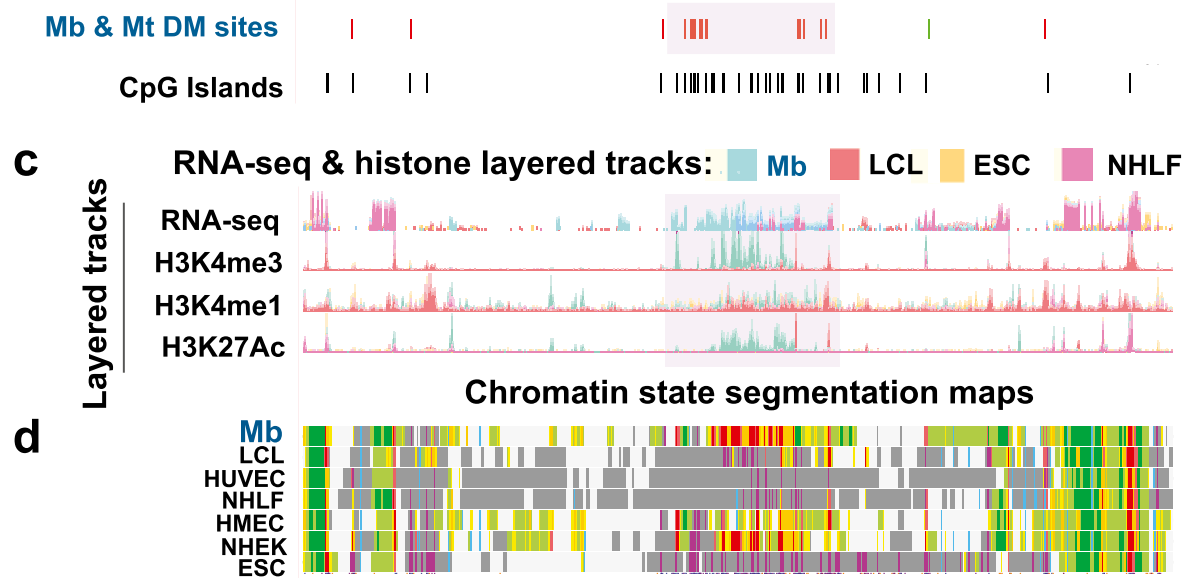

Figure 3 Myogenic hypermethylation, enrichment in CpG islands and extensive myogenesis-associated transcription localized to the 151-kb HOXC cluster. (a) MyOD binding profiles show that inferred MYOD binding sites form a distant border on both sides of the HOXC cluster. MYOD binding sites were extrapolated and are depicted as in Figure 1. The visualized chromosomal region from the UCSC Genome Browser for this figure is chr12:54,052,006-54,706,150 (654 kb). (b) 119 MbMt-hypermethylated sites and the distribution of CpG islands. (c) Layered RNA-seq track as in Figure 2 with additional layered tracks for H3K4me3, H3K4me1 and H3K27Ac by ChIP-seq (ENCODE/Broad Institute). (d) Chromatin state segmentation analysis as in Figure 1. The pink-highlighted region is the HOXC gene cluster shown in Figure 2.

previously described [35], or may help organize long-range chromatin structure around the $H O X C$ cluster. Moreover, as for all the $H O X$ clusters, the $H O X C$ region with its high concentration of CpG islands and RRBS-detected, MbMthypermethylated sites was surrounded by DNA that had a low density of both (Figure 3b).

Many of the MbMt-hypermethylated sites within the $H O X C$ gene cluster (Figure 2a, blue boxes) surround the myogenesis-associated P/E-like domain. Their location relative to chromatin epigenetic marks suggests that they are part of a boundary element preventing the spread of the central P/E-like domain and the associated high levels of expression into the adjacent chromatin (Figures 2a and $2 \mathrm{~d}$ and Additional file 4). This hypothesis would be consistent with observed negative relationships between
DNA methylation and H3K4 methylation [60]. CTCF sites often function as boundary elements or insulators [61]. There were no strong CTCF sites at the $5^{\prime}$ end of the $\mathrm{P} / \mathrm{E}$-like domain in $\mathrm{Mb}$, and there was only a constitutive CTCF site near the other end (Figure 2e, bottom, and Additional file 4).

The cluster of myogenic DM sites at the 3' border of the $\mathrm{P} / \mathrm{E}$-like domain (Figure 2a, dark blue arrow) overlapped a $\mathrm{CpG}$ island in $\mathrm{HOXC4}$ variant 1 (intron 1) and HOXC6 variant 2 (last exon; Figure 3a and ENCODE/ RNA-seq, California Institute of Technology). These genes were both preferentially expressed in $\mathrm{Mb}$ and share the same TSS. HOXC5 variant 2 shares this TSS, too, but it had no detectable transcripts according to RNA-seq data (ENCODE/California Institute of Technology and Cold 


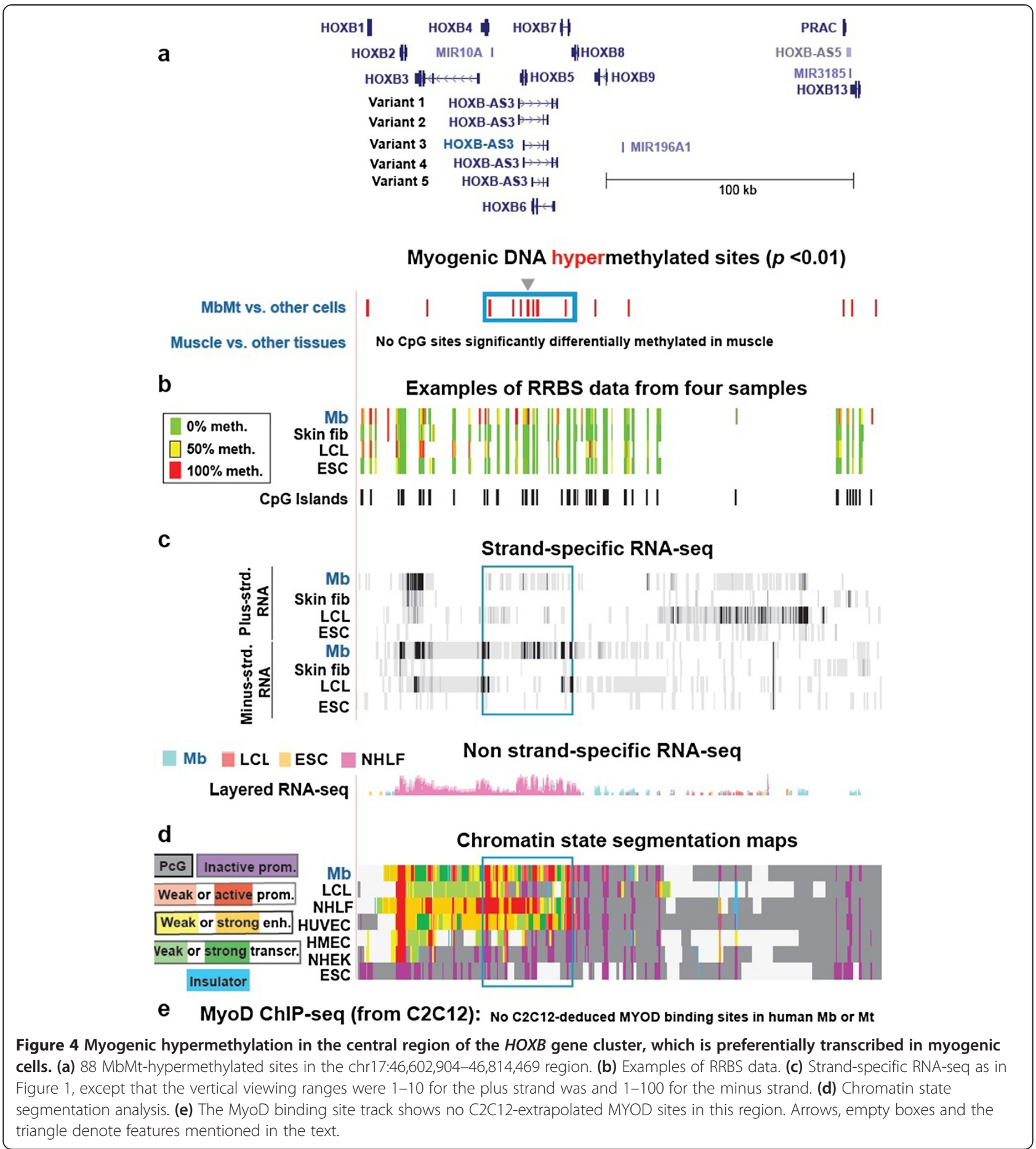

Spring Harbor Laboratory). Differential splicing will help determine relative expression of these overlapping $\mathrm{HOXC4}$, HOXC5 and HOXC6 genes. Because DNA methylation can affect the relative steady-state levels of RNA by modulating the rate of progression of the RNA polymerase II (RNA Pol II) complex in diverse ways [62,63], we hypothesize that the 41 intragenic MbMt-hypermethylated DNA sites in these three overlapping genes help regulate differential splicing in this region through effects on RNA Pol II elongation. Such effects of intragenic DNA methylation are likely to be gene-specific and/or cell type-specific $[64,65]$.

\section{Myogenic hypermethylation downstream of HOTAIR}

Near the $5^{\prime}$ end of the HOXC P/E-like domain in $\mathrm{Mb}$, there were eight MbMt-hypermethylated sites in a CpG island approximately $1 \mathrm{~kb}$ downstream of HOTAIR, a 


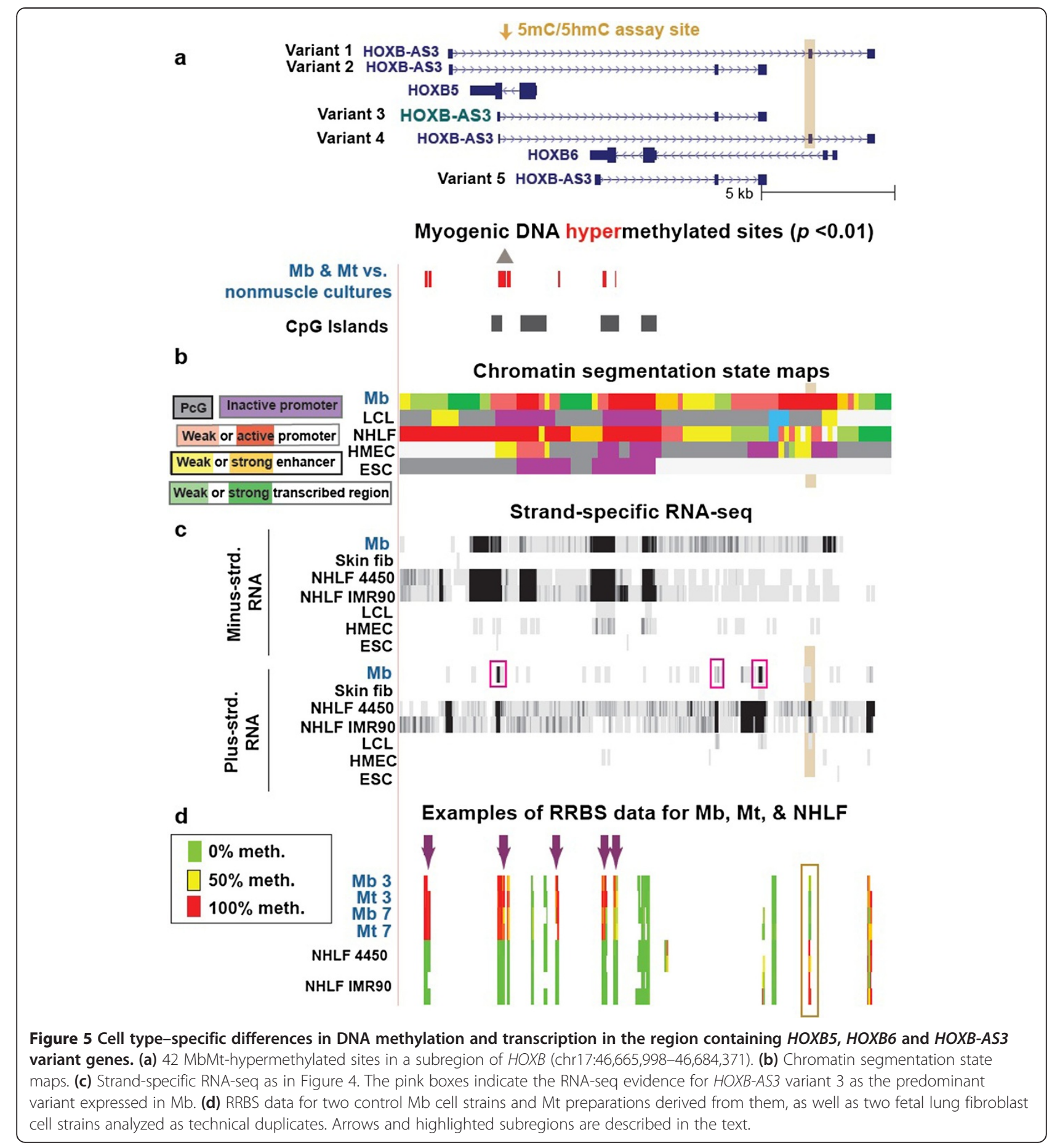

long noncoding RNA (lncRNA) gene (Figure 2a, light blue arrow, and Additional file 4). Mb displayed a moderate level of expression of HOTAIR, whereas there was little or no expression in most of the other studied cell types, with the exception of foreskin fibroblasts (Figure 2c and Additional file 1), which were highly methylated in the HOTAIR downstream region like $\mathrm{Mb}$ and $\mathrm{Mt}$ (Figure $2 \mathrm{~b}$ ). Hypermethylation of HOTAIR's 3' downstream CpG island was also seen by Lu et al. [66] in breast cancer and correlated with expression. The MbMt hypermethylation downstream of HOTAIR included the 3' half of HOXC12 (Figure 2 and Additional file 4). Lu et al. proposed that one of the functions of HOTAIR downstream methylation was to facilitate transcription termination at HOXC12. They reported no good matches in this region to DNA poly(A) signals [66] as detected by a program for predicting 


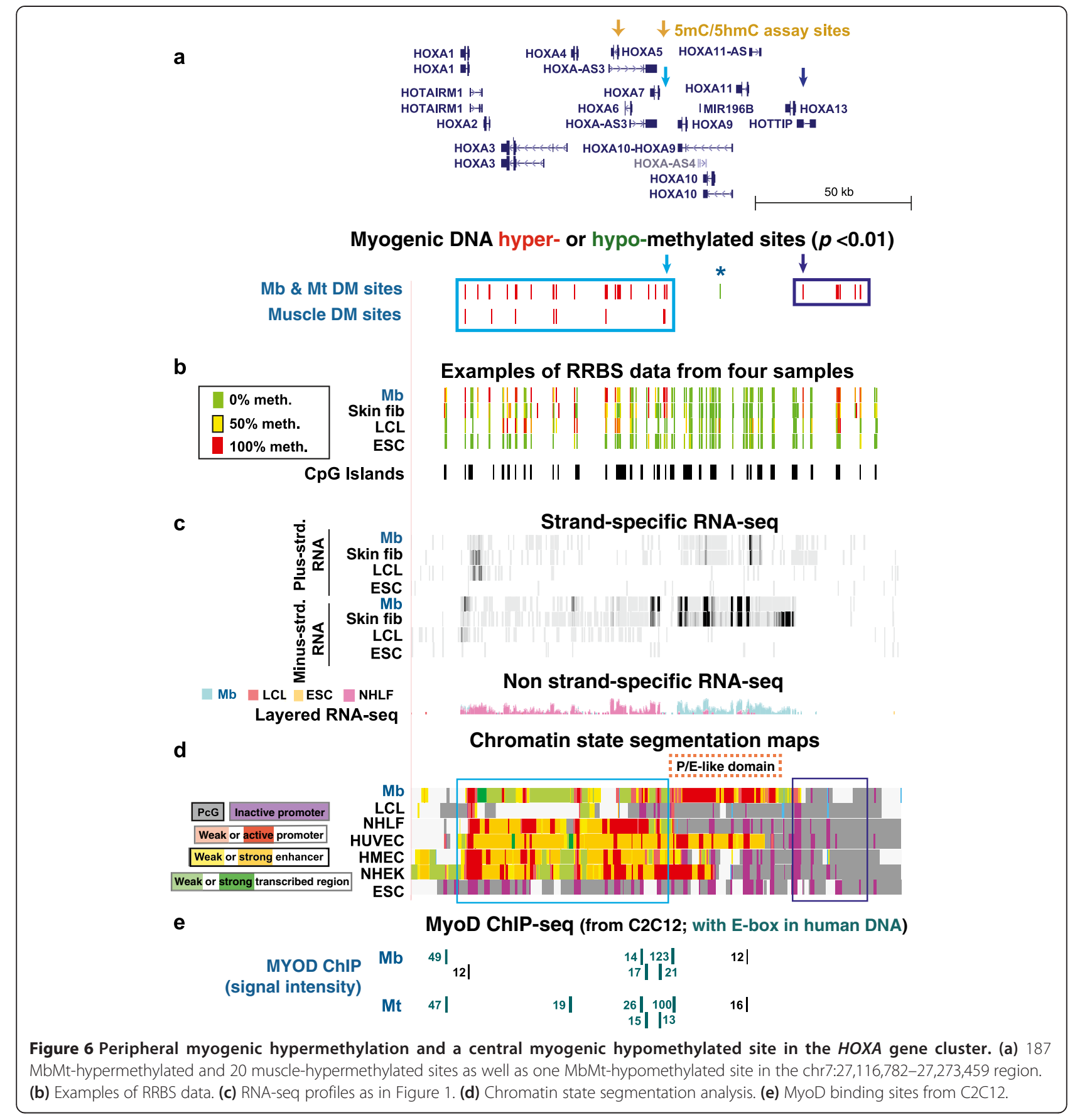

optimal AATAAA poly(A) termination signals [67]. However, we found that the program indicated two individually low-rated poly(A) signals, $9 \mathrm{bp}$ apart, $2.5 \mathrm{~kb}$ downstream from the 3 ' end of the RefSeq HOXC12 sequence. We noted that the sense transcript from $\mathrm{HOXC12}$ extends approximately to these two poly(A) signals downstream of the canonical RefSeq sequence (Additional file 4, RNA-seq, orange triangle).

We propose that DNA methylation in this $H O X C$ subregion not only acts as part of a boundary element but also facilitates transcription termination through RNA Pol II pausing at HOXC12. This in turn may favor expression of the oppositely oriented HOTAIR. In a study of mouse Hoxc6 and Hoxc8 in embryonic fibroblasts, Tao et al. provided several lines of evidence for DNA methylation causing repression at the transcription elongation step due to long-lived pausing of RNA Pol II [63]. They showed that the effect of demethylation on Hox transcription was tissue-specific and specific to individual Hox genes [65]. Consistent with the results of Tao et al., 
the $\mathrm{P} / \mathrm{E}$-like domain in $\mathrm{HOXC}$ in $\mathrm{Mb}$ includes the HOXC6 promoter region and $\mathrm{HOXC8}$, both of which were mostly or completely unmethylated and were upregulated in $\mathrm{Mb}$ and Mt vs. other cell types (Figure 2, Additional file 1, and data not shown).

HOTAIR RNA in trans represses genes across the whole HOXD gene cluster by recruiting chromatinmodifying polycomb group proteins, which results in extensive H3K27 trimethylation of the HOXD cluster [68]. We hypothesize that the preferential expression of HOTAIR that we found in myogenic progenitor cells is partly responsible for their HOXD DNA hypermethylation. This would be consistent with the recent report that knockdown of HOTAIR caused a decrease in DNA methylation of the promoter region of the PTEN gene in laryngeal squamous carcinoma cells [69].

\section{Hypermethylation and transcription in a HOXB subregion of myogenic progenitor cells}

The HOXB cluster, unlike the HOXC and HOXD clusters, displayed most of its MbMt hypermethylation in a subregion with considerable gene expression in myogenic progenitor cells, namely, the subregion containing HOXB4, HOXB5, HOXB6 and HOXB7, and HOXB$A S 3$ (Figures $4 \mathrm{a}-4 \mathrm{c}$ and Additional file 1). There was even higher expression of these genes in HUVECs or NHLFs. HOXB-AS3 transcripts in $\mathrm{Mb}$ were mostly variant 3 (Figure $5 \mathrm{c}$, pink boxes). There were $20 \mathrm{MbMt}-$ hypermethylated sites from approximately 40 to $400 \mathrm{bp}$ after the TSS of $H O X B-A S 3$ variant 3 , which overlapped the single intron and last exon of $H O X B 5$ as well as a CpG island (Figures $4 \mathrm{a}$ and $5 \mathrm{a}$, gray triangle). The higher levels of expression of HOXB5 and several variant HOXB-AS3 transcripts in NHLF vs. Mb were paralleled by a lack of methylation in this subregion in lung fibroblasts at sites that were hypermethylated in $\mathrm{Mb}$ and Mt (Figure 5d, purple arrows). The opposite DNA methylation pattern was seen at exon 2 in $H O X B-A S 3$ variants 1 and 4, where NHLF displayed DNA methylation, whereas Mb, Mt and most other cell types had little or no methylation (Figure 5, tan highlighting and data not shown). These findings could be explained most easily by the following hypothesis. DNA methylation in Mb close to the HOXB-AS3 variant 3 TSS and further upstream may be downmodulating its transcription and suppressing transcription of the other $H O X B-A S 3$ variants in $\mathrm{Mb}$, whereas DNA methylation at exon 2 in NHLF might control splicing of HOXB-AS3 transcripts specifically in those cells. Moreover, the results from NHLF suggest that antisense HOXB-AS3 transcription favors the sense $H O X B 5$ expression, as indicated by other studies of antisense vs. sense genes in $H O X$ gene clusters [58,70]. HOXB5 expression might be fine-tuned by the effects of differential methylation on the level of transcription of overlapping $H O X B-A S 3$ gene isoforms.

\section{Myogenic hypermethylated sites may serve as a boundary at the end of highly transcribed HOXA chromatin in myogenic cells}

Like the HOXC cluster, the HOXA cluster displayed much hypermethylation on both sides of a P/E-like domain in $\mathrm{Mb}$ and $\mathrm{Mt}$ (Figures $6 \mathrm{a}$ and $6 \mathrm{~d}$, boxed regions). Genes in the HOXA P/E-like domain, including HOXA9, HOXA10, HOXA11 and HOXA11-AS, were preferentially expressed in $\mathrm{Mb}$ and HUVEC vs. NHLF, an LCL, and ESC (ENCODE/RNA-seq, California Institute of Technology) and were expressed at higher levels in $\mathrm{Mb}$ than were genes bordering this domain, namely, HOXA7 and HOXA13 (Figure $6 \mathrm{c}$ and Additional files 1 and 5). Consistent with the findings for $\mathrm{Mb}$ and HUVEC, 5' Hoxa genes are involved in the skeletal muscle and endothelial cell lineages during mouse embryo development and in the adult mouse [15,71]. Between HOXA7 and HOXA9 was a cluster of $15 \mathrm{MbMt}$-hypermethylated sites and four muscle-hypermethylated sites (Figure 6a, light blue arrow, and Additional file 5). Surrounding this subregion was the highest concentration of orthologous sites for MyoD binding in the $H O X$ gene clusters (ChIP-seq profiles of $\mathrm{C} 2 \mathrm{C} 12$ mouse $\mathrm{Mb}$ and $\mathrm{Mt}$ [59]), and all of these contained centrally located, MYOD/MyoD-like CAGCTG E-box sequences (Figure 6e and Additional file 5). We propose that the clusters of MbMt-hypermethylated sites here and at the other border of the P/E-like domain help establish the boundaries of this myogenesis-associated domain either alone or in conjunction with nearby constitutive CTCF binding sites (Additional file 5 and data not shown).

\section{Myogenic hypomethylation in HOXA and extensive undermethylation in ESC and several nonembryonic cell types}

The only MbMt-hypomethylated site found in the $H O X$ gene clusters was located in the middle of the MbMtassociated P/E-like domain of the HOXA cluster (Figure 6a and Additional file 5, asterisk). This site is $1.7 \mathrm{~kb}$ upstream of the protein-encoding isoform of HOXA10 and inside the single intron of the ncRNA-encoding isoform of this gene. Hoxa10 is implicated in limb muscle development and expressed in murine hindlimb progenitor muscle cells from neonatal muscle [72]. Strand-specific RNA-seq indicates that both the IncRNA and mRNA isoforms of HOXA10 were expressed in $\mathrm{Mb}$ and HUVEC (Figure 6, and data not shown). The MbMt-hypomethylated site may be part of an extended myogenesis-associated enhancer for the HOXA1O gene in the P/E-like domain.

One of the sample types with the least DNA methylation throughout the $H O X$ clusters was ESC (Figures 1, 2, 4 and 6). Moreover, $H O X$ clusters in ESC had less DNA methylation than fibroblasts and monocytes [41]. This exceptional lack of $H O X$ DNA methylation was also seen for astrocytes, choroid plexus epithelial cells, iris pigment 
epithelial cells and retinal pigment epithelial cells (data not shown). The similar HOX DNA epigenetics of these four cell types is probably due to their common derivation from the neuroectoderm.

\section{Similarities and differences in methylation of paralogous HOX genes and comparison of Mb and ESC epigenetic marks}

$H O X$ clusters provide the opportunity to compare the epigenetics of paralogous sets of genes. Paralog group 4 $H O X$ genes all had RRBS data. Of these genes, HOXA4, HOXB4 and HOXD4 had MbMt-hypermethylated sites in the coding sequences of the last exon (Additional file 1), which encodes the homeodomain. $\mathrm{HOXC4}$ was also methylated in this subregion in $\mathrm{Mb}$ and $\mathrm{Mt}$, as were a number of other types of cell cultures, so that this subregion was not scored as hypermethylated (data not shown). Four other $H O X$ genes also had clusters of hypermethylated sites in the coding sequences of the last exon (Additional file 1).

$H O X$ gene myogenic hypermethylation was also found in gene subregions without much sequence similarity. This includes the 3 '-untranslated region ( $3^{\prime}$-UTR) of HOXB6 and HOXC5, exon 1 of HOXA6, the 2-kb upstream region of $H O X C 12$ and an internal exon (exon 3 of four exons) of HOXA3 (Additional file 1). All of these genes had mostly unmethylated CpGs detected by RRBS in $\mathrm{Mb}$ and $\mathrm{Mt}$ in their vicinity, so that the detected MbMt hypermethylation was not just due to large, continuous blocks of DNA methylation. HOXA6 and HOXC6, both of which had two exons, illustrate variety in the DNA methylation of paralogs. They exhibited, respectively, hypermethylation (and gene silencing) and little or no methylation in their first exon (and moderate gene expression) in myogenic progenitor cells (Additional file 1).

We found that subregions of H3K4me2 in ESCs often were located at MbMt-hypermethylated sites (Additional files 3, 4, 5 and 6, purple triangles). H3K4me2 marks (transcription promoting) in ESCs often overlap H3K27me3 signals (transcription repressing) and hence are called bivalent chromatin subregions that are paused for activity [17]. We hypothesize that the frequent overlap of ESC H3K4me2 with MbMt hypermethylation is due to the resolution of a bivalent chromatin mark to a univalent H3K27me3 mark with the addition of de novo DNA methylation early in the differentiation of the skeletal muscle lineage.

\section{Unusually high $5 \mathrm{hmC}$ levels at a hypermethylated site in $\mathrm{HOXB5}$ in skeletal muscle}

Because $\mathrm{Mb}$ and $\mathrm{Mt}$ have particularly high levels of the RNA encoding TET1 and TET2, enzymes that generate $5 \mathrm{hmC}$ from $5 \mathrm{mC}$ residues [11], and RRBS cannot distinguish between $5 \mathrm{hmC}$ and $5 \mathrm{mC}$ [42], it was important to determine relative amounts of these modified $\mathrm{C}$ residues at representative $H O X$ cluster sites. We quantified $5 \mathrm{mC}$ and $5 \mathrm{hmC}$ at a MbMt-hypermethylated $\mathrm{Msp}$ I site $\left(5^{\prime}-\mathrm{CCGG}-3^{\prime}\right)$ in the single introns of $\mathrm{HOXB5}$ and HOXD4, exon 1 of HOXA5, exon 2 of HOXC6, and $1.7 \mathrm{~kb}$ upstream of the TSS of HOXA7 (Figures 1, 2, 4 and 6) by an enzymatic assay that involves glucosylation of $5 \mathrm{hmC}$ by $\mathrm{T} 4$ phage $\beta$-glucosyltransferase $(\beta-\mathrm{GT}$; Epimark; New England Biolabs, Ipswich, MA, USA), digestion with MspI or HpaII and real-time PCR [11]. Using sets of samples independent from those for RRBS, the hypermethylation of these five sites in $\mathrm{Mb}$ and of the HOXD4 and HOXA7 sites in skeletal muscle was verified by this assay (Table 1). Moreover, we found that all or almost all of the hypermethylation at these sites in $\mathrm{Mb}$ was due to $5 \mathrm{mC}$ rather than to $5 \mathrm{hmC}$.

Surprisingly, only the skeletal muscle samples at the assayed CpG site in HOXB5 intron 1 displayed considerable levels of $5 \mathrm{hmC}$ ( $27 \%$ or $41 \%$ of all C as $5 \mathrm{hmC}$ ), and, remarkably, these samples exhibited more $5 \mathrm{hmC}$ than $5 \mathrm{mC}$ ( $5 \mathrm{hmC}$ and no $5 \mathrm{mC}$ or mostly $5 \mathrm{hmC}$; Table 1 ). In a previous study of genomic DNA $5 \mathrm{hmC}$ mapping in mouse embryonic stem cells (E14) ([73] and unpublished data), only about $2 \%$ of the mapped $5 \mathrm{hmC}$ sites were found to contain higher levels of $5 \mathrm{hmC}$ compared to $5 \mathrm{mC}$ using $M s p \mathrm{I}$ and HpaII differential digestion after $\beta$ glucosylation, as in this study. At the HOXB5 site analyzed in the present study, all the detected modified $C$ was $5 \mathrm{hmC}$ in the heart samples, one of the two assayed cerebellum samples and the foreskin fibroblast sample. However, the overall levels of modified $C$ in these samples were much lower than in skeletal muscle: only $1 \%$ to $6 \%$ vs. $41 \%$ to $43 \%$, respectively (Table 1 ). In a study of the HOXA gene cluster in NT2 embryonal carcinoma cells before and after retinoic acid-induced differentiation, Bocker et al. [45] found that gene activation was accompanied by conversion of much $5 \mathrm{mC}$ to $5 \mathrm{hmC}$. Their analysis involved immunoprecipitation using antibodies to $5 \mathrm{hmC}$ or $5 \mathrm{mC}$, which does not allow comparisons of relative amounts of $5 \mathrm{hmC}$ to $5 \mathrm{mC}$. Our results also indicate that some $H O X$ genes can have more genomic $5 \mathrm{hmC}$ in differentiation products than in precursor cells, although, in this case, the comparison is adult tissue to progenitor cells. This finding is also consistent with our previous demonstration that skeletal muscle had twice the average genomic $5 \mathrm{hmC}$ content of $\mathrm{Mb}$ or $\mathrm{Mt}$ in an assay of overall levels of genomic $5 \mathrm{hmC}$ [11].

\section{Conclusions}

Our profiling of differential DNA methylation in $H O X$ gene clusters suggests that myogenesis-associated hypermethylation plays diverse roles in controlling cell typespecific expression of $H O X$ genes and does not simply 
Table 1 Quantification of $5 \mathrm{mC}$ and $5 \mathrm{hmC}$ at five tested CCGG sites in the four HOX clusters

\begin{tabular}{|c|c|c|c|c|c|c|c|c|c|c|c|}
\hline \multirow{3}{*}{$\begin{array}{l}\text { Location of } \\
\text { tested site }\end{array}$} & \multicolumn{11}{|c|}{$(5 \mathrm{mC}+5 \mathrm{hmC}) /$ All C (ratio) ${ }^{\mathrm{a}}$} \\
\hline & \multicolumn{11}{|c|}{$5 h m C /(5 m C+5 h m C)(\%)$} \\
\hline & $\mathrm{Mb} 1$ & $\mathrm{Mb2}$ & Skel muscle1 & Skel muscle2 & Heart1 & Heart2 & Brain1 & Brain2 & Leuk1 & Leuk2 & Fib \\
\hline \multirow[t]{2}{*}{ HOXB5 in1 } & $0.93^{b}$ & 0.80 & 0.43 & 0.41 & 0.06 & 0.01 & 0.04 & 0 & 0.05 & 0.00 & 0.03 \\
\hline & $0 \%$ & $15 \%$ & $63 \%^{c}$ & $100 \%$ & $100 \%$ & $100 \%$ & $100 \%$ & & $0 \%$ & $0 \%$ & $100 \%$ \\
\hline \multirow[t]{2}{*}{ HOXA5 ex1 } & 0.99 & 0.96 & 0.19 & 0.04 & 0.05 & 0 & 0.02 & 0.01 & 0.97 & 0.86 & 0.02 \\
\hline & $0 \%$ & $1 \%$ & $17 \%$ & 0 & 0 & & $100 \%$ & $62 \%$ & $0 \%$ & $0 \%$ & $0 \%$ \\
\hline \multirow[t]{2}{*}{ HOXA7 upstr } & 0.99 & 0.65 & 0.55 & 0.48 & 0.01 & 0 & 0.02 & 0.01 & 0.07 & 0.02 & 0.02 \\
\hline & $0 \%$ & $1 \%$ & $15 \%$ & $0 \%$ & $0 \%$ & & $78 \%$ & $62 \%$ & $71 \%$ & $0 \%$ & $4 \%$ \\
\hline \multirow[t]{2}{*}{ HOXC6 ex2 } & 0.98 & 0.46 & 0.26 & 0.01 & 0.01 & 0 & 0.04 & 0 & 0.18 & 0.03 & 0.02 \\
\hline & $0 \%$ & $2 \%$ & $31 \%$ & $0 \%$ & $0 \%$ & & $100 \%$ & & $0 \%$ & $0 \%$ & $1 \%$ \\
\hline \multirow[t]{2}{*}{ HOXD4 in 1} & 0.98 & 0.92 & 0.78 & 0.54 & 0.08 & 0.03 & 0.05 & 0 & 0.08 & 0.01 & 1.00 \\
\hline & $0 \%$ & $0 \%$ & $10 \%$ & $0 \%$ & $48 \%$ & $0 \%$ & $100 \%$ & & $0 \%$ & $0 \%$ & $3 \%$ \\
\hline
\end{tabular}

${ }^{\mathrm{a}} 5 \mathrm{hmC}$ and $5 \mathrm{mC}$ were quantified by an enzymatic assay (Epimark; New England Biolabs) coupled with real-time PCR as described in Methods. Two biological replicates each were tested for myoblasts, skeletal muscle biopsy samples, heart and brain autopsy samples, and leukocytes. One sample of foreskin fibroblasts was assayed. The tested positions of CpG sites (in CCGG sequences) were as follows (hg19): HOXB5 intron 1, chr17:46670028; HOXA5 exon 1, chr7:27183175; HOXA7 upstream, chr7: 27197926; HOXC6 upstream, chr12:54423458; and HOXD4 intron 1, chr2:177017078. These positions are also indicated in Figures 1, 2, 4 and 6.

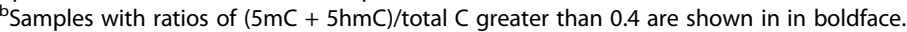

'Samples with more than $40 \%$ of modified $\mathrm{C}$ as $5 \mathrm{hmC}$ are shown in boldface.

mirror chromatin epigenetics. Specific roles for developmentally associated, differential methylation of $H O X$ gene regions would be consistent with the unusually high density of the sense and antisense genes, alternative promoters and alternative transcription termination sites in $H O X$ gene clusters [56-58] and the need for tight control of expression of these key developmental regulatory genes. For example, we found extensive DNA hypermethylation in the 3 ' half of HOXD selectively in myogenic cells and skeletal muscle tissue, whereas H3K27me3 was present throughout the HOXD gene cluster in many cell types, including $\mathrm{Mb}$ and Mt. This finding is consistent with the hypothesis that the skeletal muscle lineage needs especially tight or stable silencing of transcription of the HOXD gene cluster conferred by DNA methylation plus polycomb silencing. Moreover, our results indicate that myogenic DNA hypermethylation was often localized to bivalent ESC subregions, which may have been resolved to stably repressed subregions by de novo DNA methylation during differentiation. This is similar to a model for DNA hypermethylation of polycomb protein-controlled genes in cancer $[74,75]$. At the $H O X A$ and $H O X C$ gene clusters, the pattern of tissue-specific epigenetic marks suggests another function of myogenic DNA hypermethylation. In these gene clusters, subregions rich in myogenic DNA hypermethylation appear to be part of boundaries around a central multigenic region consisting of mostly enhancer- or promoter-type histone modifications. This DNA hypermethylation might help prevent the spreading of activating histone modifications from the central region of $H O X A$ and $H O X C$ gene clusters to their periphery.
Our study also suggests that myogenic hypermethylation of DNA might partly downregulate in cis the level of transcription of some $H O X$ antisense ncRNA genes that positively control expression of overlapping proteinencoding HOX genes, such as HOXB-AS3 and HOXB5. Myogenic hypermethylation from intragenic or intergenic locations could exert its effects on enhancers by decreasing transcription of the enhancer itself as well as by repression of canonical promoters of protein-encoding or lncRNA genes [76,77]. Moreover, our results are consistent with the hypotheses that hypermethylation within gene bodies affects which RNA isoforms are generated by modulating differential splicing and the use of alternate promoters [62,76,78,79].

Yet other relationships between differential methylation and transcription were indicated by the association of upregulation of HOTAIR in the HOXC cluster and hypermethylation of HOTAIR's immediate downstream sequences in myogenic progenitor cells and foreskin fibroblasts. In addition, the one example of myogenic hypomethylation in the $H O X$ gene clusters was in the single intron of HOXA10 in a region with the chromatin features of a myogenesis-associated enhancer. This tissuespecific DNA hypomethylation might activate or help maintain the activity of a tissue-specific enhancer, consistent with the positive association of DNA hypomethylation and inducible enhancers [80]. The dynamic nature of developmentally linked changes in DNA was evidenced by our finding that, at five tested representative $\mathrm{CpG}$ sites displaying myogenic hypermethylation, the levels of $5 \mathrm{hmC}$ were low or negligible in the skeletal muscle lineage, with the prominent exception of an intronic region in $\mathrm{HOXB5}$ 
in skeletal muscle tissue but not in muscle progenitor cells. In summary, our study of myogenesis-associated differences in DNA methylation indicates the importance of considering a wide variety of possible roles for differential DNA methylation when studying disease-linked epigenetic changes.

\section{Methods \\ Samples}

All the Mb cell strains used for methylation analysis were propagated from muscle biopsy samples that were previously described [11]. Mt samples were obtained from these myoblast cell strains by serum limitation for 5 days [11]. By immunostaining [81], we demonstrated that all batches of myoblasts contained more than 90\% desmin-positive cells and that myotube preparations had more than $75 \%$ of their nuclei in multinucleated, desmin-positive and myosin heavy chain-positive cells. Four of the nine $\mathrm{Mb}$ and $\mathrm{Mt}$ samples were Mb-Mt pairs from two normal controls, and five were from two facioscapulohumeral muscular dystrophy patients or an inclusion body myositis patient; however, all $\mathrm{Mb}$ and $\mathrm{Mt}$ samples predominantly shared the same myogenesis-associated epigenetic marks [11]. The other cell cultures for DNA methylation profiling and assessment of differential methylation in myogenic vs. nonmyogenic cell cultures and the tissue samples and the two primary (not passaged) cell cultures (hepatocytes and pancreatic islets) used for DNA methylation profiling to identify skeletal muscle-associated differential methylation were previously described normal samples [11]. All cell cultures were untransformed, except for the LCLs, which had been transformed in vitro by Epstein-Barr virus. Three control $\mathrm{Mb}$ or $\mathrm{Mt}$ samples were used for the combined data shown in DNase-seq profiles (Additional files 3, 4, 5 and 6). Two of these Mb samples and two of the Mt samples were from the same batches of cells used for RRBS. Although different sources of $\mathrm{Mb}$ and $\mathrm{Mt}$ were used for ChIP-seq, peaks of myogenesis-associated H3K4me3 or H3K4me2 usually overlapped DNase-seq peaks for these cell types (Additional files 3, 4, 5 and 6), as expected.

\section{DNA methylation profiling and statistical analyses}

For the methylation analysis, high-molecular-weight DNA was extracted, digested with $M s p I$ and used for bisulfite-based RRBS, including next-generation sequencing on an Illumina platform (Illumina Inc, San Diego, CA, USA) as previously described using the same samples as we used for our last study of myogenic differential methylation [11]. DNA methylation data for cell cultures and tissues are from the ENCODE project and available from the UCSC Genome Browser (http://genome. ucsc.edu/cgi-bin/hgTrackUi?hgsid=292099017\&c=chr1\&g= wgEncodeHaibMethylRrbs). BED files containing DNA methylation data for $5 \mathrm{Mb}$ cell strains, $5 \mathrm{Mt}$ samples (including one technical duplicate) and 47 nonmyogenic samples representing 23 unique cell lines from a variety of tissue types were aggregated into a single matrix. Rows were included for each site detected in any sample and used for assessing statistically significant differential methylation in the set of $\mathrm{Mb}$ plus Mt vs. non-muscle-cell cultures or skeletal muscle vs. non-muscle-cell cultures as previously described [11]. To increase the specificity of our analyses, we restricted our attention to those sites for which a change in methylation percentage of at least $50 \%$ was observed at a significance level of 0.01 or below. The closestBed program, (http://bedtools.readthedocs.org/en/ latest/), a member of the bedtools suite [82], was used to map each DM site to the nearest gene using both proteincoding $\left(\mathrm{NM}^{*}\right)$ and noncoding $\left(\mathrm{NR}^{*}\right)$ genes and one isoform per gene as described previously [11].

\section{Chromatin epigenetic and transcription profiling}

Data sets and sample information for histone modifications and CTCF binding, non-strand-specific RNA-seq and strand-specific RNA-seq were obtained from the ENCODE project (http://genomes.ucsc.edu/) via the laboratories of Bradley Bernstein (Broad Institute), Barbara Wold (California Institute of Technology) and Tom Gingeras (Cold Spring Harbor Laboratory), respectively. RNA-seq data were available for $\mathrm{Mb}$, but not for Mt. RNA isoform analysis and quantification were done with the CuffDiff tool [83] using the above-mentioned ENCODE non-strand-specific RNA-seq database. For cell cultures that were represented in both RNA-seq profiles (Mb, HUVEC, GM12878, NHEK, NHLF and H1 ESC), the relative expression of different cell types was similar. $\mathrm{Mb}$ and Mt samples for ENCODE histone modification and CTCF profiling and $\mathrm{Mb}$ for RNA-seq were commercially obtained, and no immunostaining was described for them. For DNaseI hypersensitivity profiling, intact nuclei were treated with DNaseI and the DNaseI-hypersensitive fraction was analyzed by next-generation sequencing as previously described ([11,84]; ENCODE (http://genome.ucsc. edu/cgi-bin/hgTrackUi?hgsid $=292099619 \& \mathrm{c}=$ chr20\&g= wgEncodeOpenChromDnase). In addition, we mined data from our previous expression profiling of $\mathrm{Mb}$ and $\mathrm{Mt}$ vs. 19 types of non-muscle-cell cultures on microarrays ([81]; GeneChip Exon 1.0 ST Array; Affymetrix, Santa Clara, CA, USA). There was overlap of three of the five control Mb or Mt samples for RRBS with the samples used for expression microarray profiling.

\section{Quantification of $5 \mathrm{hmC}$ and $5 \mathrm{mC}$ by enzymatic assay}

For analysis of the levels of $5 \mathrm{hmC}$ and $5 \mathrm{mC}$ at a given $M s p$ I site, we used an assay involving $\beta-G T$ (Epimark; New England Biolabs). After incubation or a mock enzyme incubation, aliquots were digested with MspI, which can cleave CCGG sites whether or not they are 
methylated or hydroxymethylated at the internal $\mathrm{C}$ residue, but not if they contain glucosylated $5 \mathrm{hmC}$. In parallel, digestions were done with HpaII, which can cleave CCGG sites only if they are unmodified at the internal $\mathrm{C}$, and other aliquots were used as uncut controls according to the manufacturer's instructions. Next, realtime PCR was performed and methylation status was calculated by subtraction of $\mathrm{Ct}$ values. The respective forward and reverse primers for PCR were as follows (5' to $\left.3^{\prime}\right)$ : HOXC6, ATCTTTAGGGGTCGGCTACG and CGCGTTAgGTAGCGATTGA; HOXB5, AGATG CCCACATTCAAGCTC and CAAGGGTGAGGCACT AGGAG; HOXA7 upstream, GGTGTGGAGTGAGGG ACAAC and CGATGCGACTGGGATTATTT; HOXA5, TTGCTCGCTCACGGAACTAT and TATAGACGCA CAAACGACCG; and HOXD4, GGGATTTCCAAAAT GCTTGA and ACCTCCTCAAACACACCCAC.

\section{Additional files}

Additional file 1: Table S1. Correlations between myogenic differential methylation and transcriptional up- or downregulation in myogenic vs. nonmyogenic cells.

Additional file 2: Figure S1. Myogenesis-associated DNA hypermethylation in the silenced HOXD4 region.

Additional file 3: Figure S2. Myogenic DNA hypermethylation and chromatin epigenetic marks in the HOXD1-to-MIR1OB subregion of the HOXD gene cluster.

Additional file 4: Figure S3. Myogenic DNA hypermethylation and chromatin epigenetic marks in the HOXC-AS5-to-HOXC11 subregion.

Additional file 5: Figure S4. Myogenic DNA hyper- and hypo-methylation and chromatin epigenetic marks in the HOXA-AS3-to-HOXA11 subregion.

Additional file 6: Figure S5. Myogenic DNA hypermethylation and chromatin epigenetic marks in the HOXB4-to-HOXB9 subregion.

\section{Abbreviations}

3'-UTR: 3'-untranslated region; 5hmC: 5-hydroxymethylcytosine; $5 \mathrm{mC}$ : 5-methylcytosine; ChIP-seq: Chromatin immunoprecipitation/next-generation DNA sequencing; DM: Differentially methylated; ESC: $\mathrm{H} 1$ embryonic stem cell; Fib2: Foreskin fibroblasts; GM12878: Lymphoblastoid cell line produced from blood by Epstein-Barr virus transformation; $\beta$-GT: $\beta$-glucosyltransferase; H3K27Ac: Histone H3 lysine 27 acetylation; H3K27me3: histone H3 lysine 27 trimethylation; H3K4me1: Histone $\mathrm{H} 3$ lysine 4 monomethylation; H3K4me3: Histone H3 lysine 4 trimethylation; HMEC: Human mammary epithelial cell; HUVEC: Human umbilical cord endothelial cells;

LCL: Lymphoblastoid cell line; IncRNA: long noncoding RNA; Mb: myoblast; MbMt: Set of myoblasts plus myotubes; Mt: Myotube; ncRNA: Noncoding RNA; NHEK: Normal human epidermal keratinocyte; NHLF: Normal human lung fibroblast; PcG: Polycomb group; P/E-like domain: Promoter- and enhancer-type chromatin in a multigenic region; RNA Pol II: RNA polymerase II; RRBS: Reduced representation bisulfite sequencing; SA epith: Small airway epithelial cell; TSS: transcription start site.

\section{Competing interests}

The authors declare that they have no competing interests.

\section{Authors' contributions}

$K T$ prepared and immunocytochemically evaluated the Mb and Mt samples and helped with the Cufflinks analysis. CB and ML did the statistical analyses. JT, ZS and SP were responsible for the $5 \mathrm{hmC}$ and $5 \mathrm{mC}$ quantification. SC and CR helped with the bioinformatics analyses. LS and GEC did the DNasel hypersensitivity profiling. LS did the liftover of C2C12 MyoD coordinates to the human genome. ME did bioinformatics analyses and wrote the manuscript. All authors read and approved the final manuscript.

\section{Acknowledgments}

For making their data (http://genome.ucsc.edu/) available prepublication, we thank the ENCODE Chromatin Group at the Broad Institute and Massachusetts Institute of Technology (Bradley Bernstein's and Manolis Kellis's groups) and the ENCODE Transcription Group at the California Institute of Technology (Barbara Wold's group) and the Cold Spring Harbor Laboratory (Tom Gingeras's group). We are grateful to the ENCODE DNA Methylation Group at the HudsonAlpha Institute for Biotechnology (Rick Myers's Group) for the initial collaboration on RRBS [11] and to Melody Badoo for help with the Cufflinks program update. This research was supported in part by a grant from the National Institutes of Health to ME (NS04885).

\section{Author details}

'Hayward Human Genetics Program and Tulane Cancer Center, Tulane Health Sciences Center, New Orleans LA, USA. ${ }^{2}$ Tulane Cancer Center and Department of Mathematics, Tulane Health Sciences Center and Tulane University, New Orleans, LA, USA. ${ }^{3}$ New England Biolabs, Ipswich MA, USA. ${ }^{4}$ Institute for Genome Sciences \& Policy, Duke University, Durham, NC, USA ${ }^{5}$ Center for Bioinformatics and Genomics, Tulane Health Sciences Center, New Orleans, LA, USA.

Received: 5 April 2013 Accepted: 21 June 2013 Published: 2 August 2013

\section{References}

1. Mallo M, Wellik DM, Deschamps J: Hox genes and regional patterning of the vertebrate body plan. Dev Biol 2010, 344:7-15.

2. Foronda D, de Navas LF, Garaulet DL, Sánchez-Herrero E: Function and specificity of Hox genes. Int J Dev Biol 2009, 53:1404-1419.

3. Barber BA, Rastegar M: Epigenetic control of Hox genes during neurogenesis, development, and disease. Ann Anat 2010, 192:261-274.

4. Noordermeer D, Leleu M, Splinter E, Rougemont J, De Laat W, Duboule D: The dynamic architecture of Hox gene clusters. Science 2011, 334:222-225.

5. Ladd-Acosta C, Pevsner J, Sabunciyan S, Yolken RH, Webster MJ, Dinkins T, Callinan PA, Fan JB, Potash JB, Feinberg AP: DNA methylation signatures within the human brain. Am J Hum Genet 2007, 81:1304-1315.

6. Meissner A, Mikkelsen TS, Gu H, Wernig M, Hanna J, Sivachenko A, Zhang X, Bernstein BE, Nusbaum C, Jaffe DB, Gnirke A, Jaenisch R, Lander ES: Genome-scale DNA methylation maps of pluripotent and differentiated cells. Nature 2008, 454:766-770.

7. De Bustos C, Ramos E, Young JM, Tran RK, Menzel U, Langford CF, Eichler EE, Hsu L, Henikoff S, Dumanski JP, Trask BJ: Tissue-specific variation in DNA methylation levels along human chromosome 1. Epigenetics Chromatin 2009, $2: 7$

8. Ji H, Ehrlich LI, Seita J, Murakami P, Doi A, Lindau P, Lee H, Aryee MJ, Irizarry RA, Kim K, Rossi DJ, Inlay MA, Serwold T, Karsunky H, Ho L, Daley GQ, Weissman IL, Feinberg AP: Comprehensive methylome map of lineage commitment from haematopoietic progenitors. Nature 2010, 467:338-342.

9. Varley KE, Gertz J, Bowling KM, Parker SL, Reddy TE, Pauli-Behn F, Cross MK Williams BA, Stamatoyannopoulos JA, Crawford GE, Absher DM, Wold BJ, Myers RM: Dynamic DNA methylation across diverse human cell lines and tissues. Genome Res 2013, 23:555-567.

10. Kang JS, Krauss RS: Muscle stem cells in developmental and regenerative myogenesis. Curr Opin Clin Nutr Metab Care 2010, 13:243-248.

11. Tsumagari K, Baribault C, Terragni J, Varley KE, Gertz J, Pradhan S, Baddoo M, Crain CM, Song L, Crawford GE, Myers RM, Lacey M, Ehrlich M: Early de novo DNA methylation and prolonged demethylation in the muscle lineage. Epigenetics 2013, 8:317-332.

12. Maconochie M, Nonchev S, Morrison A, Krumlauf R: Paralogous Hox genes: function and regulation. Annu Rev Genet 1996, 30:529-556.

13. Akbas GE, Taylor HS: HOXC and HOXD gene expression in human endometrium: lack of redundancy with HOXA paralogs. Biol Reprod 2004, 70:39-45.

14. Zakany J, Duboule D: The role of Hox genes during vertebrate limb development. Curr Opin Genet Dev 2007, 17:359-366.

15. Houghton $L$, Rosenthal N: Regulation of a muscle-specific transgene by persistent expression of Hox genes in postnatal murine limb muscle. Dev Dyn 1999, 216:385-397. 
16. Yamamoto M, Kuroiwa A: Hoxa-11 and Hoxa-13 are involved in repression of MyoD during limb muscle development. Dev Growth Differ 2003, 45:485-498.

17. Kashyap V, Gudas LJ, Brenet F, Funk P, Viale A, Scandura JM: Epigenomic reorganization of the clustered Hox genes in embryonic stem cells induced by retinoic acid. J Biol Chem 2011, 286:3250-3260.

18. Novotny E, Compton S, Liu PP, Collins FS, Chandrasekharappa SC: In vitro hematopoietic differentiation of mouse embryonic stem cells requires the tumor suppressor menin and is mediated by Hoxa9. Mech Dev 2009, 126:517-522.

19. Golpon HA, Geraci MW, Moore MD, Miller HL, Miller GJ, Tuder RM, Voelkel NF: HOX genes in human lung: altered expression in primary pulmonary hypertension and emphysema. Am J Pathol 2001, 158:955-966.

20. Kelly M, Daftary G, Taylor HS: An autoregulatory element maintains HOXA10 expression in endometrial epithelial cells. Am J Obstet Gynecol 2006, 194:1100-1109.

21. Rancourt DE, Tsuzuki T, Capecchi MR: Genetic interaction between hoxb-5 and hoxb- 6 is revealed by nonallelic noncomplementation. Genes Dev 1995, 9:108-122

22. Björnsson JM, Larsson N, Brun AC, Magnusson $M$, Andersson $E$, Lundström $P$, Larsson J, Repetowska E, Ehinger M, Humphries RK, Karlsson S: Reduced proliferative capacity of hematopoietic stem cells deficient in Hoxb3 and Hoxb4. Mol Cell Biol 2003, 23:3872-3883.

23. Biressi S, Tagliafico E, Lamorte G, Monteverde S, Tenedini E, Roncaglia E, Ferrari S, Ferrari S, Cusella-De Angelis MG, Tajbakhsh S, Cossu G: Intrinsic phenotypic diversity of embryonic and fetal myoblasts is revealed by genome-wide gene expression analysis on purified cells. Dev Biol 2007, 304:633-651.

24. Lacombe J, Hanley O, Jung H, Philippidou P, Surmeli G, Grinstein J, Dasen JS: Genetic and functional modularity of $\mathrm{Hox}$ activities in the specification of limb-innervating motor neurons. PLoS Genet 2013, 9:e1003184.

25. Lawrence HJ, Stage KM, Mathews CH, Detmer K, Scibienski R, MacKenzie M, Migliaccio E, Boncinelli E, Largman C: Expression of HOX C homeobox genes in lymphoid cells. Cell Growth Differ 1993, 4:665-669.

26. Garcia-Gasca A, Spyropoulos DD: Differential mammary morphogenesis along the anteroposterior axis in Hoxc6 gene targeted mice. Dev Dyn 2000, 219:261-276.

27. Rieger E, Bij JJ, van Oostveen JW, Soyer HP, Oudejans CB, Jiwa NM, Walboomers JM, Meijer CJ: Expression of the homeobox gene HOXC4 in keratinocytes of normal skin and epithelial skin tumors is correlated with differentiation. J Invest Dermatol 1994, 103:341-346.

28. Delpretti S, Zakany J, Duboule D: A function for all posterior Hoxd genes during digit development? Dev Dyn 2012, 241:792-802.

29. Bernstein BE, Kamal M, Lindblad-Toh K, Bekiranov S, Bailey DK, Huebert DJ, McMahon S, Karlsson EK, Kulbokas EJ 3rd, Gingeras TR, Schreiber SL, Lander ES: Genomic maps and comparative analysis of histone modifications in human and mouse. Cell 2005, 120:169-181.

30. Wang P, Lin C, Smith ER, Guo H, Sanderson BW, Wu M, Gogol M, Alexander T, Seidel C, Wiedemann LM, Ge K, Krumlauf R, Shilatifard A: Global analysis of H3K4 methylation defines MLL family member targets and points to a role for MLL1-mediated H3K4 methylation in the regulation of transcriptional initiation by RNA polymerase II. Mol Cell Biol 2009, 29:6074-6085.

31. Zhang Y, Liu Z, Medrzycki M, Cao K, Fan Y: Reduction of Hox gene expression by histone $\mathrm{H} 1$ depletion. PLoS One 2012, 7:e38829.

32. Kim K, Lee HC, Park JL, Kim M, Kim SY, Noh SM, Song KS, Kim JC, Kim YS: Epigenetic regulation of microRNA-10b and targeting of oncogenic MAPRE1 in gastric cancer. Epigenetics 2011, 6:740-751.

33. Wang KC, Yang YW, Liu B, Sanyal A, Corces-Zimmerman R, Chen Y, Lajoie BR, Protacio A, Flynn RA, Gupta RA, Wysocka J, Lei M, Dekker J, Helms JA, Chang HY: A long noncoding RNA maintains active chromatin to coordinate homeotic gene expression. Nature 2011, 472:120-124.

34. Rinn JL, Bondre C, Gladstone HB, Brown PO, Chang HY: Anatomic demarcation by positional variation in fibroblast gene expression programs. PLoS Genet 2006, 2:e119.

35. Tschopp P, Duboule D: A genetic approach to the transcriptional regulation of Hox gene clusters. Annu Rev Genet 2011, 45:145-166.

36. Chambeyron S, Da Silva NR, Lawson KA, Bickmore WA: Nuclear re-organisation of the Hoxb complex during mouse embryonic development. Development 2005, 132:2215-2223.

37. Avraham A, Sandbank J, Yarom N, Shalom A, Karni T, Pappo I, Sella A, Fich A Walfisch S, Gheber L, Evron E: A similar cell-specific pattern of HOXA methylation in normal and in cancer tissues. Epigenetics 2010, 5:41-46.
38. Hershko AY, Kafri T, Fainsod A, Razin A: Methylation of HoxA5 and HoxB5 and its relevance to expression during mouse development. Gene 2003 , 302:65-72.

39. Yamagishi T, Ozawa M, Ohtsuka C, Ohyama-Goto R, Kondo T: Evx2-Hoxd13 intergenic region restricts enhancer association to Hoxd13 promoter. PLoS One 2007, 2:e175.

40. Illingworth R, Kerr A, Desousa D, Jorgensen H, Ellis P, Stalker J, Jackson D, Clee C, Plumb R, Rogers J, Humphray S, Cox T, Langford C, Bird A: A novel CpG island set identifies tissue-specific methylation at developmental gene loci. PLOS Biol 2008, 6:e22

41. Laurent L, Wong E, Li G, Huynh T, Tsirigos A, Ong CT, Low HM, Kin Sung KW, Rigoutsos I, Loring J, Wei CL: Dynamic changes in the human methylome during differentiation. Genome Res 2010, 20:320-331.

42. Stroud H, Feng S, Morey Kinney S, Pradhan S, Jacobsen SE: 5-Hydroxymethylcytosine is associated with enhancers and gene bodies in human embryonic stem cells. Genome Biol 2011, 12:R54

43. Guo JU, Su Y, Zhong C, Ming GL, Song H: Hydroxylation of 5-methylcytosine by TET1 promotes active DNA demethylation in the adult brain. Cell 2011, 145:423-434

44. Globisch D, Munzel M, Muller M, Michalakis S, Wagner M, Koch S, Bruckl T, Biel M, Carell T: Tissue distribution of 5-hydroxymethylcytosine and search for active demethylation intermediates. PLoS One 2011, 5:e15367.

45. Bocker MT, Tuorto F, Raddatz G, Musch T, Yang FC, Xu M, Lyko F, Breiling A Hydroxylation of 5-methylcytosine by TET2 maintains the active state of the mammalian HOXA cluster. Nat Commun 2012, 3:818.

46. Szulwach KE, Li X, Li Y, Song CX, Han JW, Kim S, Namburi S, Hermetz K, Kim JJ, Rudd MK, Yoon YS, Ren B, He C, Jin P: Integrating 5-hydroxymethylcytosine into the epigenomic landscape of human embryonic stem cells. PLoS Genet 2011, 7:e1002154

47. Moroni MC, Vigano MA, Mavilio F: Regulation of the human HOXD4 gene by retinoids. Mech Dev 1993, 44:139-154.

48. Vrba L, Garbe JC, Stampfer MR, Futscher BW: Epigenetic regulation of normal human mammary cell type-specific miRNAs. Genome Res 2011, 21:2026-2037.

49. ENCODE Project Consortium, Myers RM, Stamatoyannopoulos J, Snyder M, Dunham I, Hardison RC, Bernstein BE, Gingeras TR, Kent WJ, Birney E, Wold B, Crawford GE, Bernstein BE, Epstein CB, Shoresh N, Ernst J, Mikkelsen TS, Kheradpour P, Zhang X, Wang L, Issner R, Coyne MJ, Durham T, Ku M, Truong T, Ward LD, Altshuler RC, Lin MF, Kellis M, Gingeras TR, Davis CA, et al: A user's guide to the encyclopedia of DNA elements (ENCODE). PLOS Biol 2011, 9:e1001046.

50. Roberts A, Trapnell C, Donaghey J, Rinn JL, Pachter L: Improving RNA-Seq expression estimates by correcting for fragment bias. Genome Biol 2011, 12:R22.

51. Soshnikova N, Duboule D: Epigenetic regulation of vertebrate Hox genes a dynamic equilibrium. Epigenetics 2009, 4:537-540.

52. Hagarman JA, Motley MP, Kristjansdottir K, Soloway PD: Coordinate regulation of DNA methylation and $\mathrm{H} 3 \mathrm{~K} 27 \mathrm{me} 3$ in mouse embryonic stem cells. PLoS One 2012, 8:e53880.

53. Reddington JP, Perricone SM, Nestor CE, Reichmann J, Youngson NA, Suzuki M, Reinhardt D, Dunican DS, Prendergast JG, Mjoseng H, Ramsahoye BH, Whitelaw E, Greally JM, Adams IR, Bickmore WA, Meehan RR: Redistribution of $\mathrm{H} 3 \mathrm{~K} 27$ me3 upon DNA hypomethylation results in de-repression of Polycomb target genes. Genome Biol 2013, 14:R25.

54. Ernst J, Kheradpour P, Mikkelsen TS, Shoresh N, Ward LD, Epstein CB, Zhang X, Wang L, Issner R, Coyne M, Ku M, Durham T, Kellis M, Bernstein BE: Mapping and analysis of chromatin state dynamics in nine human cell types. Nature 2011, 473:43-49.

55. Pekowska A, Benoukraf T, Zacarias-Cabeza J, Belhocine M, Koch F, Holota H, Imbert J, Andrau JC, Ferrier P, Spicuglia S: H3K4 tri-methylation provides an epigenetic signature of active enhancers. EMBO J 2011, 30:4198-210.

56. Mercer TR, Gerhardt DJ, Dinger ME, Crawford J, Trapnell C, Jeddeloh JA, Mattick JS, Rinn JL: Targeted RNA sequencing reveals the deep complexity of the human transcriptome. Nat Biotechnol 2012, 30:99-104.

57. Coulombe Y, Lemieux M, Moreau J, Aubin J, Joksimovic M, Berube-Simard FA, Tabaries S, Boucherat O, Guillou F, Larochelle C, Tuggle CK, Jeannotte L: Multiple promoters and alternative splicing: Hoxa5 transcriptional complexity in the mouse embryo. PLoS One 2010, 5:e10600.

58. Sessa L, Breiling A, Lavorgna G, Silvestri L, Casari G, Orlando V: Noncoding RNA synthesis and loss of Polycomb group repression accompanies the colinear activation of the human HOXA cluster. RNA 2007, 13:223-239. 
59. Cao Y, Yao Z, Sarkar D, Lawrence M, Sanchez GJ, Parker MH, MacQuarrie KL Davison J, Morgan MT, Ruzzo WL, Gentleman RC, Tapscott SJ: Genomewide MyoD binding in skeletal muscle cells: a potential for broad cellular reprogramming. Dev Cell 2010, 18:662-674.

60. Cheng $X$, Blumenthal RM: Coordinated chromatin control: structural and functional linkage of DNA and histone methylation. Biochemistry 2010 49:2999-3008.

61. Phillips JE, Corces VG: CTCF: master weaver of the genome. Cell 2009, 137:1194-1211.

62. Shukla S, Kavak E, Gregory M, Imashimizu M, Shutinoski B, Kashlev M, Oberdoerffer P, Sandberg R, Oberdoerffer S: CTCF-promoted RNA polymerase II pausing links DNA methylation to splicing. Nature 2011, 479:74-79.

63. Tao $Y, X i$ S, Briones $V$, Muegge $K$ : Lsh mediated RNA polymerase II stalling at HoxC6 and HoxC8 involves DNA methylation. PLoS One 2011, 5:e9163.

64. Nguyen CT, Gonzales FA, Jones PA: Altered chromatin structure associated with methylation-induced gene silencing in cancer cells: correlation of accessibility, methylation, MeCP2 binding and acetylation. Nucleic Acids Res 2001, 29:4598-4606.

65. Xi S, Zhu H, Xu H, Schmidtmann A, Geiman TM, Muegge K: Lsh controls Hox gene silencing during development. Proc Natl Acad Sci USA 2007 104:14366-14371.

66. Lu L, Zhu G, Zhang C, Deng Q, Katsaros D, Mayne ST, Risch HA, Mu L, Canuto EM, Gregori G, Benedetto C, Yu H: Association of large noncoding RNA HOTAIR expression and its downstream intergenic CpG island methylation with survival in breast cancer. Breast Cancer Res Treat 2012, 136:875-883.

67. Liu H, Han H, Li J, Wong L: DNAFSMiner: a web-based software toolbox to recognize two types of functional sites in DNA sequences. Bioinformatics 2005, 21:671-673.

68. Rinn JL, Kertesz M, Wang JK, Squazzo SL, Xu X, Brugmann SA, Goodnough LH, Helms JA, Farnham PJ, Segal E, Chang HY: Functional demarcation of active and silent chromatin domains in human HOX loci by noncoding RNAs. Cell 2007, 129:1311-1323.

69. Li D, Feng J, Wu T, Wang Y, Sun Y, Ren J, Liu M: Long intergenic noncoding RNA HOTAIR is overexpressed and regulates PTEN methylation in laryngeal squamous cell carcinoma. Am J Pathol 2013, 182:64-70.

70. Sasaki YT, Sano M, Kin T, Asai K, Hirose T: Coordinated expression of ncRNAs and HOX mRNAs in the human HOXA locus. Biochem Biophys Res Commun 2007, 357:724-730.

71. Trivedi CM, Patel RC, Patel CV: Homeobox gene HOXA9 inhibits nuclear factor-KB dependent activation of endothelium. Atherosclerosis 2007, 195:e50-e60.

72. Porter JD, Israel S, Gong B, Merriam AP, Feuerman J, Khanna S, Kaminski HJ: Distinctive morphological and gene/protein expression signatures during myogenesis in novel cell lines from extraocular and hindlimb muscle. Physiol Genomics 2005, 24:264-275.

73. Sun Z, Terragni J, Borgaro JG, Liu Y, Yu L, Guan S, Wang H, Sun D, Cheng X, Zhu Z, Pradhan S, Zheng Y: High-resolution enzymatic mapping of genomic 5-hydroxymethylcytosine in mouse embryonic stem cells. Cell Rep 2013, 3:567-576.

74. Baylin SB: Stem cells, cancer, and epigenetics. In The Stem Cell Research Community, Stem Book. Edited by Jaenisch R, Laird P. 2009. doi:10.3824/ stembook.1.50.1. Available at: http://www.stembook.org/sites/default/files/ pubnode/59012d58e397f06325596210a30ad7790cd314c0/Baylin_Final_ proofs/Stem_cells_cancer_and_epigenetics/Stem_cells_cancer_and_ epigenetics.pdf.

75. Easwaran H, Johnstone SE, Van Neste L, Ohm J, Mosbruger T, Wang Q, Aryee MJ, Joyce P, Ahuja N, Weisenberger D, Collisson E, Zhu J, Yegnasubramanian S, Matsui W, Baylin SB: A DNA hypermethylation module for the stem/progenitor cell signature of cancer. Genome Res 2012, 22:837-849.

76. Maunakea AK, Nagarajan RP, Bilenky M, Ballinger TJ, D'Souza C, Fouse SD, Johnson BE, Hong C, Nielsen C, Zhao Y, Turecki G, Delaney A, Varhol R, Thiessen N, Shchors K, Heine VM, Rowitch DH, Xing X, Fiore C, Schillebeeckx M, Jones SJ, Haussler D, Marra MA, Hirst M, Wang T, Costello JF: Conserved role of intragenic DNA methylation in regulating alternative promoters. Nature 2010, 466:253-257.

77. Kolovos P, Knoch TA, Grosveld FG, Cook PR, Papantonis A: Enhancers and silencers: an integrated and simple model for their function. Epigenetics Chromatin 2012, 5:1
78. Rauch TA, Wu X, Zhong X, Riggs AD, Pfeifer GP: A human B cell methylome at 100-base pair resolution. Proc Natl Acad Sci USA 2009, 106:671-678.

79. Sati S, Tanwar VS, Kumar KA, Patowary A, Jain V, Ghosh S, Ahmad S, Singh M, Reddy SU, Chandak GR, Raghunath M, Sivasubbu S, Chakraborty K, Scaria V, Sengupta S: High resolution methylome map of rat indicates role of intragenic DNA methylation in identification of coding region. PLOS One 2012, 7:e31621.

80. Taube JH, Allton K, Duncan SA, Shen L, Barton MC: Foxa1 functions as a pioneer transcription factor at transposable elements to activate Afp during differentiation of embryonic stem cells. J Biol Chem 2010, 285:16135-16144.

81. Tsumagari K, Chang SC, Lacey M, Baribault C, Chittur SV, Sowden J, Tawil R, Crawford GE, Ehrlich M: Gene expression during normal and FSHD myogenesis. BMC Med Genomics 2011, 4:67.

82. Quinlan AR, Hall IM: BEDTools: a flexible suite of utilities for comparing genomic features. Bioinformatics 2010, 26:841-842

83. Trapnell C, Roberts A, Goff L, Pertea G, Kim D, Kelley DR, Pimentel H, Salzberg SL, Rinn JL, Pachter L: Differential gene and transcript expression analysis of RNA-seq experiments with TopHat and Cufflinks. Nat Protoc 2012, 7:562-578.

84. Song L, Zhang Z, Grasfeder LL, Boyle AP, Giresi PG, Lee BK, Sheffield NC, Gräf S, Huss M, Keefe D, Liu Z, London D, McDaniell RM, Shibata Y, Showers KA, Simon JM, Vales T, Wang T, Winter D, Zhang Z, Clarke ND, Birney E, lyer VR, Crawford GE, Lieb JD, Furey TS: Open chromatin defined by DNasel and FAIRE identifies regulatory elements that shape cell-type identity. Genome Res 2011, 21:1757-1767.

doi:10.1186/1756-8935-6-25

Cite this article as: Tsumagari et al: DNA methylation and differentiation: HOX genes in muscle cells. Epigenetics \& Chromatin 2013 6:25

\section{Submit your next manuscript to BioMed Central and take full advantage of:}

- Convenient online submission

- Thorough peer review

- No space constraints or color figure charges

- Immediate publication on acceptance

- Inclusion in PubMed, CAS, Scopus and Google Scholar

- Research which is freely available for redistribution 